\title{
EFFECTS OF WORK-RELATED SLEEP RESTRICTION ON ACUTE PHYSIOLOGICAL AND PSYCHOLOGICAL STRESS RESPONSES AND THEIR INTERACTIONS: A REVIEW AMONG EMERGENCY SERVICE PERSONNEL
}

\author{
ALEXANDER WOLKOW ${ }^{1,2}$, SALLY FERGUSON ${ }^{2,3}$, BRAD AISBETT $^{1,2}$, and LUANA MAIN ${ }^{1}$ \\ ${ }^{1}$ Deakin University, Burwood, Australia \\ Centre for Physical Activity and Nutrition Research, School of Exercise and Nutrition Sciences \\ ${ }^{2}$ Bushfire Co-Operative Research Centre, East Melbourne, Australia \\ ${ }^{3}$ Central Queensland University, Wayville, Australia \\ Appleton Institute
}

\begin{abstract}
Emergency work can expose personnel to sleep restriction. Inadequate amounts of sleep can negatively affect physiological and psychological stress responses. This review critiqued the emergency service literature (e.g., firefighting, police/law enforcement, defense forces, ambulance/paramedic personnel) that has investigated the effect of sleep restriction on hormonal, inflammatory and psychological responses. Furthermore, it investigated if a psycho-physiological approach can help contextualize the significance of such responses to assist emergency service agencies monitor the health of their personnel. The available literature suggests that sleep restriction across multiple work days can disrupt cytokine and cortisol levels, deteriorate mood and elicit simultaneous physiological and psychological responses. However, research concerning the interaction between such responses is limited and inconclusive. Therefore, it is unknown if a psycho-physiological relationship exists and as a result, it is currently not feasible for agencies to monitor sleep restriction related stress based on psycho-physiological interactions. Sleep restriction does however, appear to be a major stressor contributing to physiological and psychological responses and thus, warrants further investigation.
\end{abstract}

Key words:

Sleep, Cytokines, Stress, Cortisol, Mood, Psycho-physiological

\section{INTRODUCTION AND REVIEW OBJECTIVES}

Inadequate sleep quality and quantity is a common problem in modern society, which, in turn, can negatively affect psychological and physiological functioning [1]. Evidence suggests that periods of partial and total sleep deprivation/restriction can impair immune function (e.g., above and below normal pro- and anti-inflammatory cytokine levels) [2,3], hormone secretion (e.g., higher and flatter diurnal cortisol levels) [4,5] and instigate adverse psychological changes (e.g., symptoms of anxiety and

This review was completed as part of a lead author's (Alexander Wolkow) PhD.

Received: February 18, 2014. Accepted: August 13, 2014.

Corresponding author: A. Wolkow, Centre for Physical Activity and Nutrition Research School of Exercise and Nutrition Sciences, Deakin University, 221 Burwood Hwy, Burwood, VIC 3125, Australia (e-mail: awolkow@deakin.edu.au). 
depression) [1,6-9]. Furthermore, an increasing body of evidence has demonstrated a link between sleep restriction and negative long-term physical and mental health outcomes [2,10-16]. For instance, inadequate or disrupted sleep has been associated with cardiovascular and metabolic diseases [10,12,14-16], and depression [6-8]. Worldwide, cardiovascular diseases (CVDs) are the leading cause of death [17], while depression remains the leading cause of disability [18]. The links that exist between widespread chronic, long-term negative health outcomes and sleep, underscore the need to examine and characterize acute psychological and physiological stress responses to sleep restriction and deprivation.

To fully evaluate and understand the relationship between acute sleep restriction and physical and mental health, an integrated approach that takes into account both acute psychological and physiological responses to this stressor should be considered. While the understanding of how stress affects psycho-physiological responses and their interaction is still limited, specific findings suggest that psychological health and well-being may influence physiological processes and vice versa [19-21]. Indeed, evidence suggests that an increase in stress exposure simultaneously induces both physiological (i.e., higher and flatter diurnal cortisol levels and/or abnormally high or low cytokine levels) and psychological changes (i.e., mood and behavioral disturbances), and that these responses can be positively or negatively correlated with one another [22-25].

Under normal circumstances, cytokines and glucocorticoids (e.g., cortisol) form a feedback loop, whereby stress elicits the release of pro-inflammatory cytokines which activate the hypothalamic pituitary adrenal (HPA)-axis and results in the release of cortisol and anti-inflammatory cytokines [26-29]. In turn, cortisol and anti-inflammatory cytokines negatively feedback to suppress and regulate the inflammatory response [26-29]. However, exposure to intense or prolonged stress can disrupt this feedback loop causing an enhanced/up-regulated inflammatory state and HPA-axis disturbances [28,30,31].

These maladaptations are typically associated with negative physiological (e.g., CVD and metabolic syndrome) and psychological health outcomes (e.g., depression) [28,32,33], and in chronic situations, may be underlying these stress-related diseases [30,31,34,35]. For instance, elevated levels of sleep regulating cytokines interleukin (IL)-6, IL-1 $\beta$ and TNF- $\alpha$ have been positively associated with CVD [36-38], metabolic syndrome [39] and depression [40,41]. Furthermore, higher, flatter diurnal cortisol patterns have been related to depression [42,43]. Other distinctive parts of the cortisol stress response such as elevated morning cortisol levels measured in plasma have also been positively associated with CVD and metabolic syndrome related features (e.g., glucose intolerance, insulin sensitivity, hypertension, atherosclerosis) [44-46]. Despite these associations, the exact direction and magnitude of a 'normal' acute change in cytokine, cortisol and mood responses to different periods of sleep restriction is largely unknown, as is the degree to which these acute stress responses are quantifiable risk factors to health [47]. Accordingly, an integrated approach that combines assessment of multiple responses and their interactions may help evaluate and assist in contextualizing the significance of these stress responses $[24,25,28,48,49]$ to sleep restriction.

One of the most common causes of inadequate sleep are work-related factors [50]. For instance, early start times and shift work can cause a misalignment to the circadian rhythm of physiological functions [50]. Reduced sleep opportunities, as a result of extended work hours, long commutes, overtime and being on-call can also disrupt sleep [50]. In addition, exposure to environmental (e.g., light and noise), physical (e.g., intense physical work) and/or psychological (e.g., critical decisions, life threatening situations) work-related stressors can disrupt the circadian rhythm and prevent adequate 
sleep [14,50,51]. Emergency (e.g., firefighting, law enforcement/police, some emergency medical services) and defense force services (e.g., military, navy, army) are a unique group of occupations in which personnel is exposed to non-standard scheduling of work hours whilst completing physical work demands on a daily basis [5258]. For instance, emergency personnel can perform long hours of intermittent physically intense work (up to 15-h) with little rest between consecutive shifts, which can last up to a week [55,56,59-61].

Furthermore, some personnel have reported that the constant readiness (i.e., hyper-vigilance) to respond to an emergency alarm felt while on-duty can transfer to the off-duty environment [62]. This state of hyper-vigilance in combination with excessive work hours and exposure to other occupational stressors, could place personnel of these physically demanding occupations at an increased risk of suffering from inadequate sleep. Indeed, a higher prevalence of sleep disturbances has been reported among firefighting, police, paramedic and military personnel when compared to other occupations $[60,61,63-$ 66]. For the purpose of this review, further mention of 'emergency services' or 'emergency personnel' will refer to firefighting, police, paramedic/ambulance and defense force personnel, unless stated otherwise.

The high prevalence of adverse long-term health outcomes (e.g., CVD, metabolic syndrome and depression) associated with sleep restriction reported among these occupations [67-70] is of further concern for emergency services. For instance, Courtney et al. [68] have found paramedic personnel in Australia to have a higher prevalence of sleep-related mental health outcomes (i.e., depression and anxiety) when compared to community samples. Furthermore, the findings among police have revealed that officers reporting shorter sleep durations had a significantly greater number of metabolic syndrome related factors when compared to non-police workers [71] or officers who received more sleep [72].
Given the high prevalence of sleep restriction $[61,63,64]$ and negative sleep-related health outcomes reported among emergency personnel [67-70], it is important to understand how work-related sleep restriction affects personnel's acute psychological and physiological stress responses. Therefore, the 1st part of this review will identify and critique any gaps in the available occupational-based literature that has investigated the effects of sleep restriction on acute hormonal, inflammatory and psychological (i.e., mood, anxiety levels, perceived stress) responses among personnel of emergency services. This review is focused on understanding how personnel respond to modest periods of chronic sleep restriction (i.e., 1-7 nights) that could reflect a single shift, a working week or deployment to a large emergency event (e.g., large bushfires/wildfires). Therefore, research investigating extended periods of reduced sleep (e.g., 8-week military training) will not be examined in this review. Furthermore, the independent influence that night-shifts in emergency work have on stress responses is beyond the scope of this review and therefore, will not be evaluated.

There is growing support in the literature to simultaneously measure multiple responses and their interactions to assess the relevance/importance of stress responses $[28,73]$. Accordingly, it would be valuable for services to know whether a psycho-physiological approach can help contextualize the significance of acute stress responses to sleep restriction and therefore, assist services to efficiently monitor the acute health of their personnel in the field. For example, if exposure to work-related stressors such as sleep restriction elicits similar or related psychological and physiological responses, then monitoring the health of personnel could be achieved by using self-report measures (e.g., psychological questionnaires). Physiological assessments (e.g., blood samples) could then compliment these measures to provide a more complete picture of the personnel's stress related health. 
Therefore, the 2nd part of this review will interrogate the pertinent emergency service-based literature to determine if a psycho-physiological approach can help contextualize the significance of any acute stress responses to assist emergency services monitor the health of their personnel.

While this review intends to provide a comprehensive evidence-based inclusive of various emergency-based occupations, the sleep and stress response research to date has focused mainly on soldiers. Consequently, the balance of literature in this review from each uniform service reflects what is currently available. Furthermore, where emergency-specific research is not available, findings from the wider stress response literature that has investigated periods of sleep restriction similar in length to that demonstrated during emergency work (i.e., 1-7 nights) will be reviewed, and where possible, their transferability to personnel in emergency occupations will be examined.

\section{MATERIAL AND METHODS}

\section{Study selection and literature search strategy}

This narrative review searched for sleep and stress-related research conducted in emergency-based occupations, the duties of which could be described as physically demanding. Although narrative, the source articles were identified using a systematic search strategy of the global database
Ebsco Host to search health-related databases (Academic Search Complete, The Allied and Complementary Medicine Database, CINAHL, Global Health, Health Source (Consumer and Nursing/Academic Editions), MasterFILE, MEDLINE/PubMed, PsycARTICLES, PsycBOOKS, PsycEXTRA, Psychology and Behavioral Sciences, PsycINFO, PsychTESTS and SPORTDiscus) to identify relevant English-language studies published between January 1985 and September 2013.

The occupation-based key words used for the search included: 'firefighters', 'fire fighters', 'fire-fighters', 'police', 'law enforcement', 'paramedics', 'ambulance personnel', 'soldiers', 'navy', 'military' and 'defense force' searched together with sleep and stress response related words of key interest that included: 'sleep deprivation', 'sleep restriction', 'cortisol', 'cytokines', 'mood' and 'psycho-physiological'. Each of the key words mentioned was searched for individually and in conjunction with each other. In addition, relevant articles were identified from the references provided in the original articles retrieved.

The search results were screened and obviously irrelevant or duplicate articles were omitted. Further articles from non-peer-reviewed sources were excluded from the search results. Abstracts and full-texts of the remaining results were then scanned and included in the final review if they met the inclusion criteria outlined in Table 1.

Table 1. Inclusion criteria for the literature review

\begin{tabular}{|c|c|}
\hline Inclusion criteria & Explanation \\
\hline Participants & $\begin{array}{l}\text { active duty emergency (e.g., firefighting, police/law enforcement, paramedic/ambulance } \\
\text { personnel, rescue workers) or defense force (e.g., army, navy) personnel in physically } \\
\text { demanding occupations or healthy adults exposed to periods of sleep restriction similar } \\
\text { to emergency personnel (see below) }\end{array}$ \\
\hline Period of sleep restriction/deprivation & complete or partial sleep restriction (i.e., $<7 \mathrm{~h}$ sleep) from 1-8 consecutive nights \\
\hline Shift type & $\begin{array}{l}\text { single day or consecutive shifts with periods of restricted sleep } \\
\text { no specific night shifts }\end{array}$ \\
\hline Physiological stress responses & pro- and/or anti-inflammatory cytokines and/or cortisol \\
\hline Psychological stress responses & $\begin{array}{l}\text { a valid and reliable subjective mood, behavior and/or anxiety questionnaire (e.g., Profile } \\
\text { of Mood States, Brunel Mood Scale, State-Trait Anxiety Inventory) }\end{array}$ \\
\hline
\end{tabular}




\section{RESULTS AND DISCUSSION}

\section{The impact of work-related sleep restriction \\ on physiological stress responses \\ among emergency service personnel}

Sleep restriction and changes to cortisol

Despite the high prevalence of sleep disturbances reported among police [61,64,65], firefighting [66], paramedic [60] and military personnel [74,75], only one emergency service-based study has investigated the specific effect of restricted sleep on physiological stress responses [76]. Goh et al. [76] have found no significant difference in the overall daily cortisol levels between control (i.e., $8 \mathrm{~h}$ sleep) and sleep deprived military personnel (i.e., 1 night of total sleep deprivation). Though there was a significant increase in cortisol levels at 1:30 p.m. on the day after sleep deprivation [76].

Similar results for daily cortisol levels have been found in non-emergency service-based investigations [77-79], indicating that in isolation, a single night of complete sleep restriction may not be a sufficient stressor to significantly affect the overall diurnal release of cortisol among emergency personnel. Determining the isolated (i.e., with no other significant external physical or psychological stressors present) effect that controlled periods of shortened sleep may have on emergency responders' physiological responses is difficult due to their multi-stressor environments (e.g., emergency incidents that can last hours or days and expose personnel to sleep deprivation and physical work) $[52,60,61]$ and consequently, it has not been investigated to a great extent. However, the findings from multi-day military studies may provide some insight into the possible effect restricted sleep opportunities between periods of physical work and military-related demands (e.g., food and water restriction) have on stress responses.

To date, several studies have investigated soldiers' hormonal changes in response to receiving as little as 1-2-h of total sleep across the course of near continuous physical training spanning 3-7 days [80,81]. For instance, Opstad and Aakvaag [81] have reported that the normal circadian variation in the morning and evening cortisol levels on day 1 and 4 of the military training disappeared, indicating an abnormal circadian cortisol release (Table 2). In a more recent study, Opstad [80] employed a high frequency cortisol sampling method to further investigate the effect of a similar 5-day physical training course with minimal sleep (i.e., 1-3-h of total sleep over the course) on military cadets' circadian cortisol release (Table 2). Similar to control conditions (i.e., no physical training and an 8-h sleep opportunity), cortisol levels followed a normal diurnal rhythm on day 1 of the course. However, throughout the rest of the course, mean cortisol levels remained consistently elevated $(+130-140 \%)$ and over the final 24 -h period, the circadian rhythm had almost disappeared [80]. Moreover, 4-5 days after completing the course the circadian cortisol rhythm remained significantly different from the control period [80], adding further support to the possibility of a disrupted circadian cortisol rhythm following consecutive days of sleep restriction during military training. Neither study [80,81], however, controlled for sleep duration or frequency. Instead, the participants slept when possible between training activities and it was estimated by the authors that the participants obtained 1-3-h of total sleep over the course [80,81]. The lack of control over sleep variables (i.e., timing, duration and frequency) limits the ability to make definite conclusions regarding whether sleep duration, frequency and/or rhythm disruption influenced the diurnal dysregulation of cortisol or not.

Furthermore, the participants were also performing physical work and had a substantially restricted daily energy intake during the training course $[80,81]$. These factors potentially confound the interpretation of these findings, as exposure to physical work and energy restriction has also been found to disrupt normal diurnal cortisol 


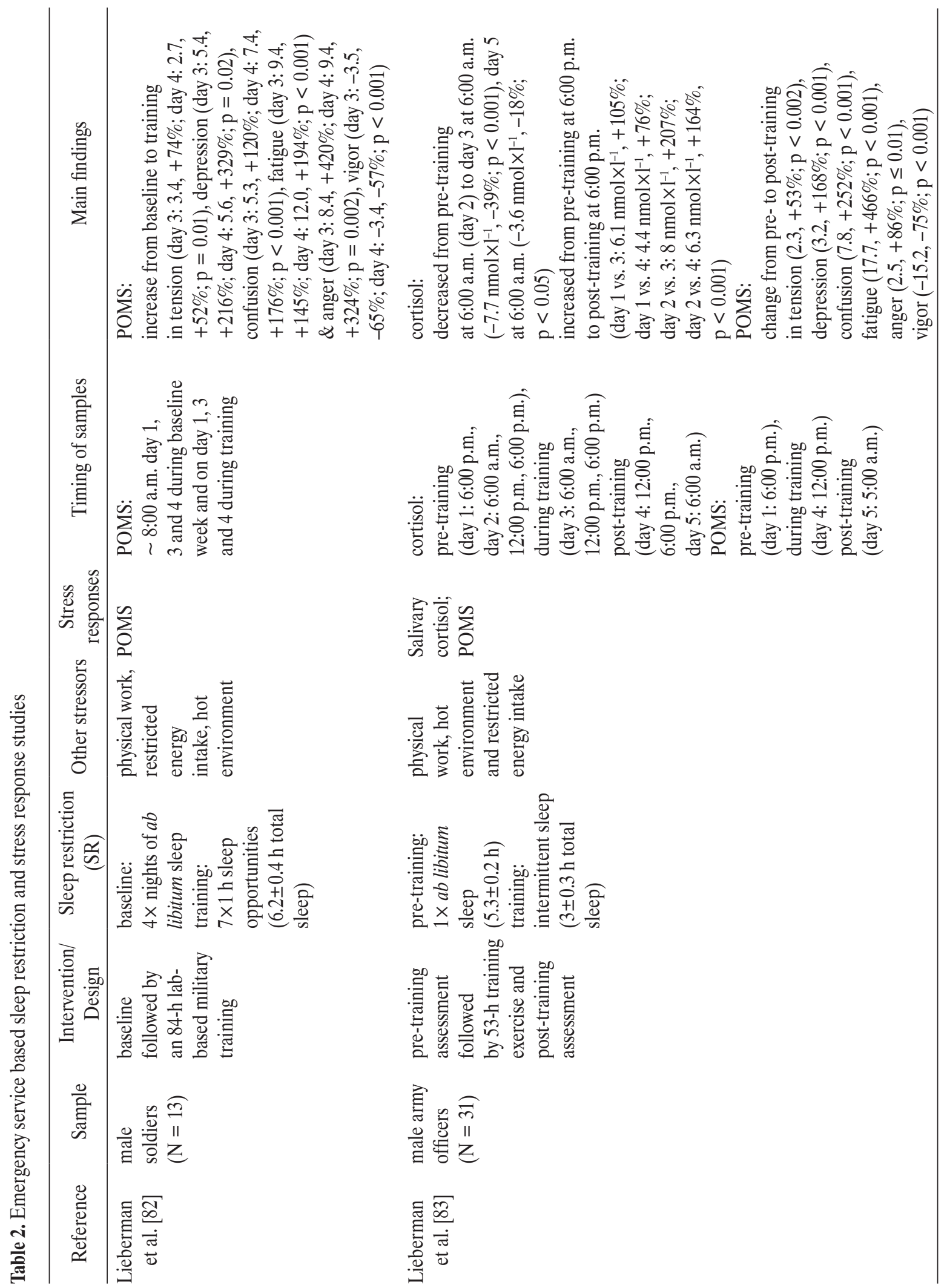



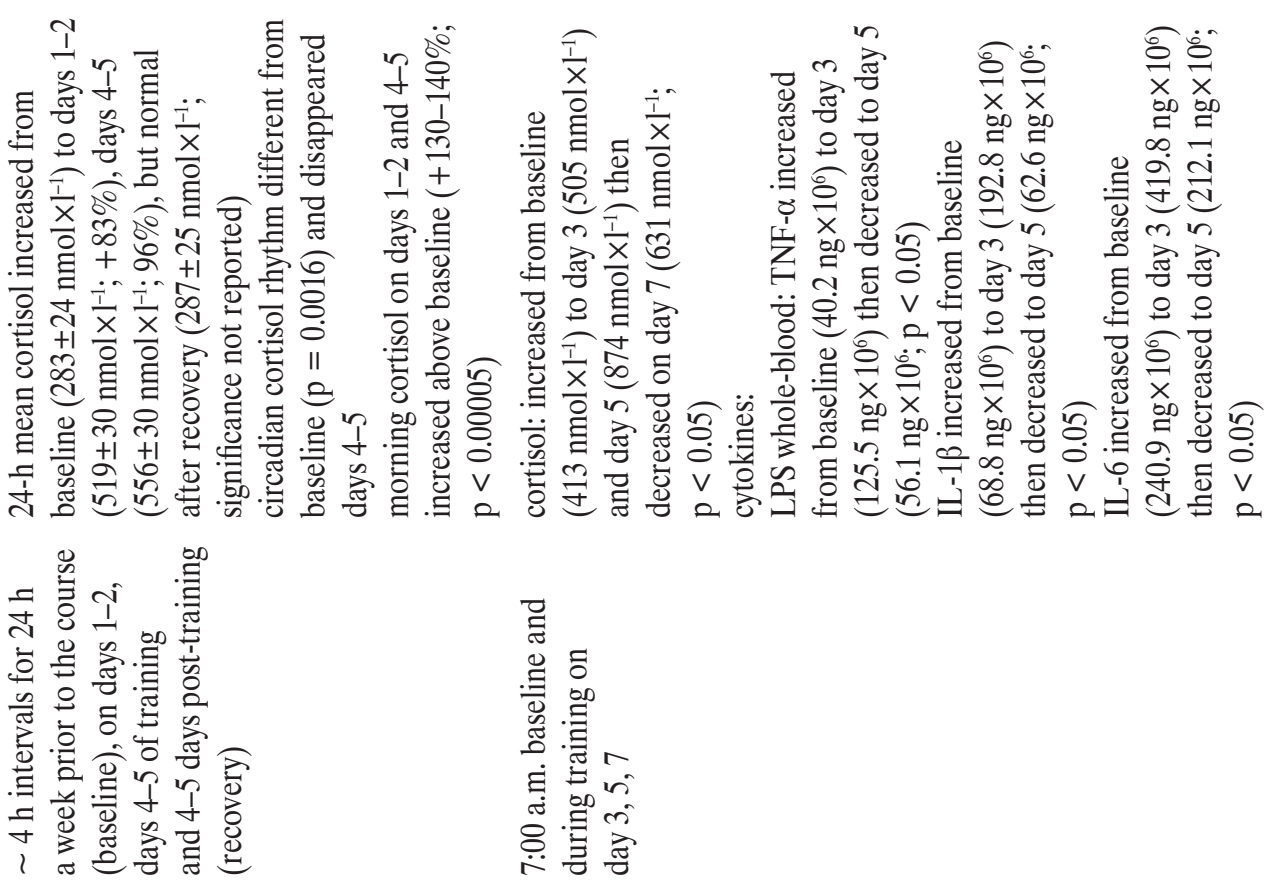

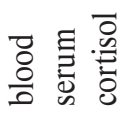

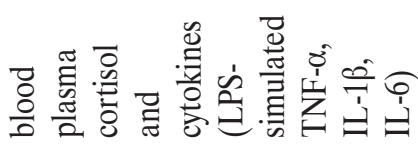

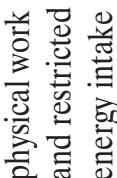

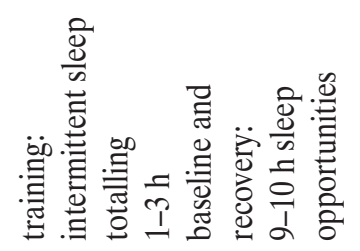
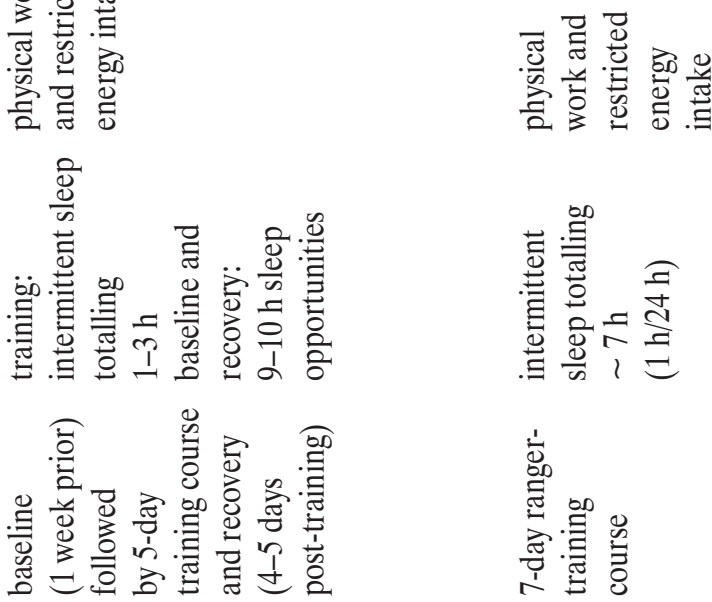

兽离

宊

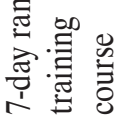

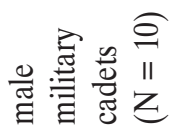

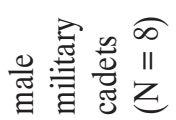

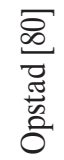

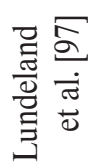




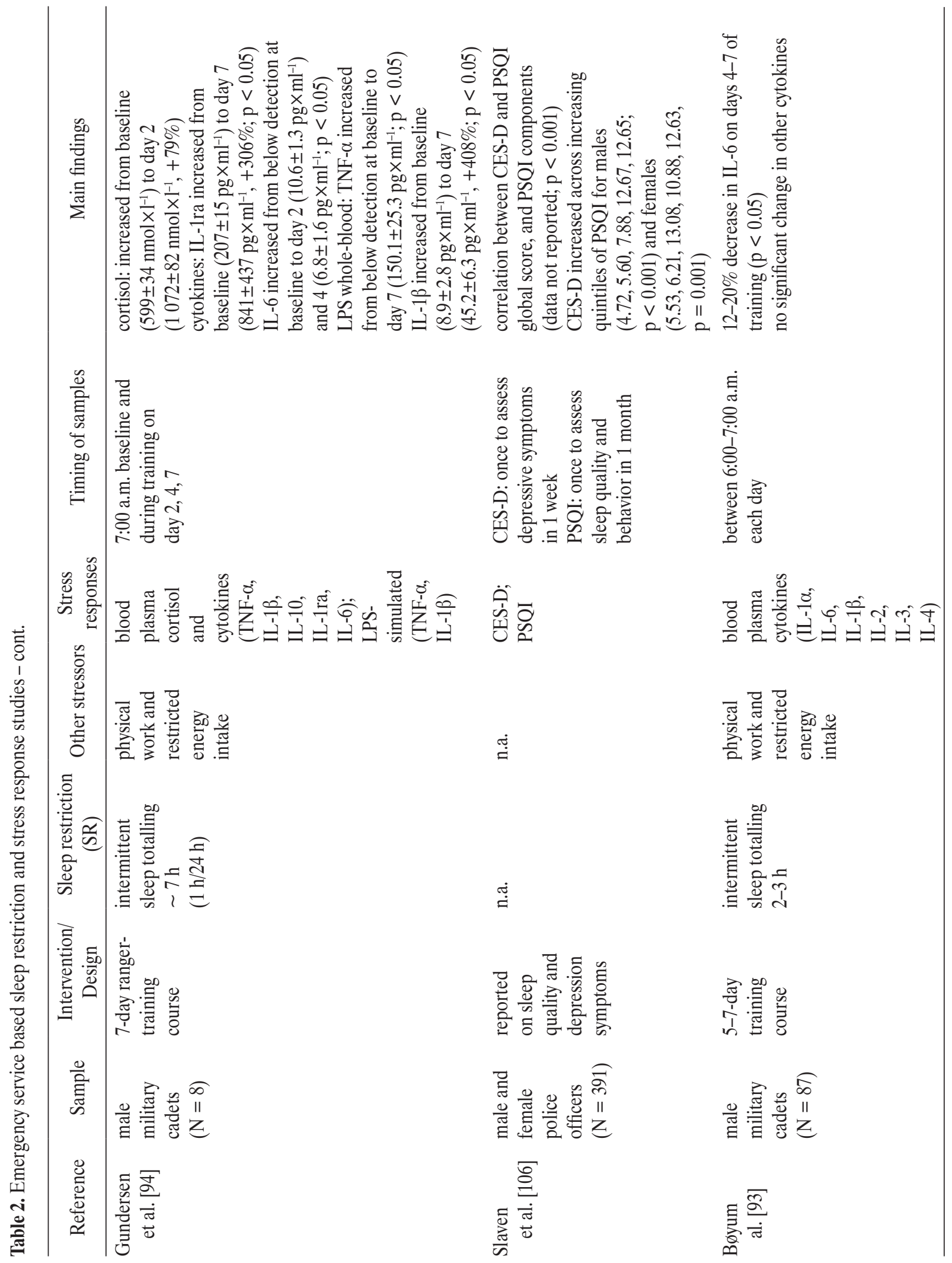


㐘

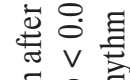

드ㅇㅡㅗㄹ

की

党

西 +0

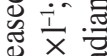

$\overline{5}$ 응

的可

유류

。ㄹㅇㅇㅛ

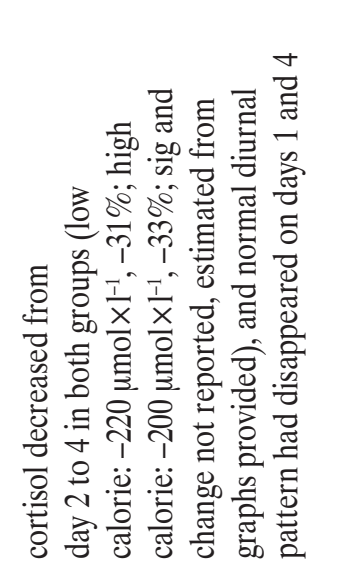

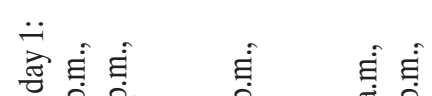

造芒

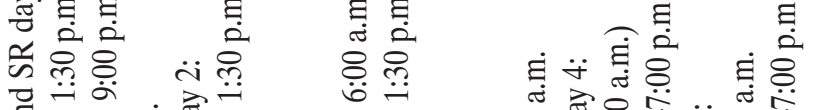

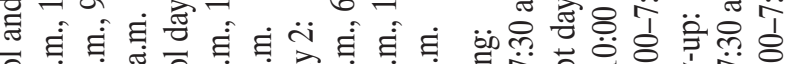

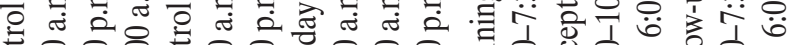

ठั

逽总

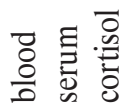

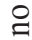

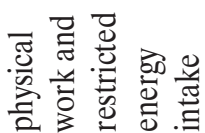

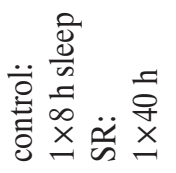

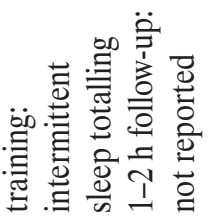

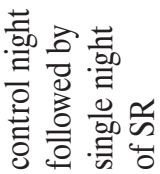

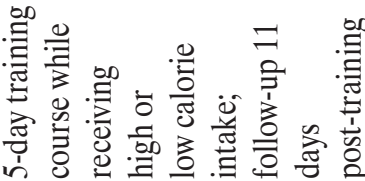

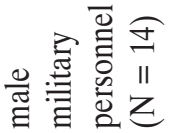

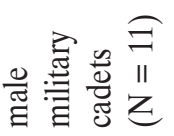

$\frac{\sqrt{\frac{0}{0}}}{\frac{\pi}{0}}$

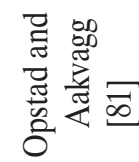


levels $[84,85]$. Therefore, which stressor or combination of stressors has the greatest effect on the participants' cortisol response remains to be determined.

Although both Opstad [80] and Opstad and Aakvaag [81] have observed a dysregulated cortisol response, different discrete parts of the cortisol circadian cycle were investigated in each study. For instance, in the more recent study, Opstad [80] has reported that daily cortisol secretion increased significantly over the 5-day training course, while the earlier study [81] reported a decline in the morning (i.e., 8:00 a.m.) cortisol production. Both increases and decreases in cortisol level have been demonstrated following stress exposure and could indicate allostatic load (i.e., wear and tear) on the endocrine system expressed as either an intensified or suppressed cortisol production $[86,87]$. The increased acute daily levels of cortisol have been associated with insulin resistance, which could accelerate the progression of type II diabetes, atherosclerosis and hypertension $[44,45,88]$.

Conversely, persons exposed to chronic stress have demonstrated inadequate morning (salivary) cortisol levels one hour after awakening [89]. McEwen and Seeman [90] define an inadequate cortisol response as a form of allostatic load that occurs when the HPA-axis produces too little cortisol in response to a stressor, which as a result, causes immune mediators (e.g., inflammatory cytokines) and other systems that are normally contained by cortisol, to become overactive. Consequently, hyperactivity of these systems can increase the risk of auto-immune and inflammatory disorders (e.g., rheumatoid arthritis and multiple sclerosis) [27,90].

Methodological differences between the studies cited above could have contributed to the conflicting results for cortisol. For instance, single day cortisol sampling implemented by Opstad and Aakvaag [81] provides less stable measures of cortisol when compared to a multiday sampling assessment [91], such as that adopted by Opstad [80]. Furthermore, the morning rise in cortisol known as the cortisol awakening response depends closely on awakening time [92]. Therefore, variation in diurnal cortisol demonstrated between these studies could be also due to the differences in the time of cortisol sample collection after awakening. For instance, Opstad [80] and Opstad and Aakvaag [81] collected morning cortisol at 8:00 a.m. and between 6:30 and 7:30 a.m. respectively, yet neither study reported when the participants slept, limiting the ability to take into account what effect awakening time had on the morning cortisol levels in these studies. In addition, cortisol was examined by both Opstad [80] and Opstad and Aakvaag [81] using blood, while Goh et al. [76] used saliva samples. Evidence suggests that a high cortisol response can occur among individuals as a result of drawing blood (i.e., venepuncture) [79]. Therefore, the sampling methods could further explain different findings for cortisol between these studies [76,80,81].

The mixed findings for diurnal cortisol could also be due to differences in the duration and frequency of sleep deprivation and restriction examined. For instance, Goh et al. [76] have reported that a single night of total sleep deprivation had no effect on overall diurnal cortisol levels. Meanwhile, significant changes were reported following extreme periods of sleep restriction endured over consecutive days examined in the military training studies $[80,81]$.

\section{Sleep restriction and changes to cytokines}

To date, research has investigated what impact sleep restriction during military operations has on pro- and antiinflammatory cytokines [93,94]. For instance, Bøyum et al. [93] have investigated IL-6, IL-1 $\alpha$, IL-1 $\beta$, IL-2 and IL-4 levels among military cadets before and during 5-7 days of a continuous military training combined with sleep (i.e., 2-3-h of total sleep) and calories restriction. Bøyum et al. [93] have found a $-12-20 \%$ reduction in IL-6 on days 4-7 ( $<$ 0.05) (Table 2) [93], but no 
change in any of the other investigated markers. The decline in IL-6 is in contrast to the findings from the modest (3-6-h sleep per night) sleep restriction studies of similar duration, which have demonstrated an increase in daily cytokine levels among healthy adults following sleep deprivation $[3,95,96]$.

Furthermore, Gundersen et al. [94] have found IL-6 levels to significantly increase from baseline to days 2 $\left(10.6 \pm 1.3 \mathrm{pg} \times \mathrm{ml}^{-1}\right)$ and $4\left(+6.8 \pm 1.6 \mathrm{pg} \times \mathrm{ml}^{-1}\right)$ (Table 2) during a 7-day training course that comprised almost identical sleep restriction periods and physical work intensities to those investigated by Opstad et al. [80,81]. However, by completion of the course, IL-6 had returned to baseline levels [94]. In contrast, IL-1ra levels have been reported by Gundersen et al. [94] to increase throughout the training course $(+306 \%$; $p<0.05)$ (Table 2). Furthermore, the pro-inflammatory cytokines TNF- $\alpha$ (from below detection to $150.1 \pm 25.3 \mathrm{pg} \times \mathrm{ml}^{-1}$; $\mathrm{p}<0.05)$ and IL-1 $(+408 \%$; $<<0.05)$ were found to increase from baseline to completion of the training course (Table 2) [94].

Using an almost identical training protocol, Lundeland et al. [97] have investigated cadets' IL-6, TNF- $\alpha$ and IL-1 $\beta$ levels in LPS-simulated whole blood (Table 2). Findings for IL- 6 were similar to those of Gundersen et al. [94], whereas TNF- $\alpha$ and IL-1 $\beta$ levels were also found to increase from baseline to day $3(+212 \%$ and $+180 \%$, respectively), then decreased to day 5 ( $-55 \%$ and $-68 \%$, respectively; $p<0.05$ ) [97]. The increase and then the decrease in cytokine levels could indicate either an adaptation to the training course or possibly, failure to continue the same workload, however, this is difficult to determine with no performance data presented [97].

Interestingly, Bøyum et al. [93] have observed contrasting findings for IL- 6 when compared to the studies by Gundersen et al. [94] and Lundeland et al. [97]. The decline in IL- 6 observed by Bøyum et al. [93] over a short duration (i.e., 4-7 days) of activity was unexpected and suggested by the authors [93] to be a result of plasma expansion due to excessive water intake. This particular cytokine does however, have both anti- and pro-inflammatory actions in the immune response [98]. Therefore, the significant reduction in IL- 6 could indicate possible dysregulation of the immune system.

While no emergency service research has examined the effect of sleep restriction on inflammatory cytokines in a controlled setting, the findings from the wider stress response literature indicate that pro-inflammatory cytokines IL-6, IL-1 $\beta$, IL-1ra and TNF- $\alpha$ significantly increase or decrease from baseline following single [77,99] as well as multiple nights [100] of complete and partial sleep restriction among healthy subjects. For instance, a single 40 -h period of total sleep deprivation caused an $+89 \%$ increase from baseline in TNF- $\alpha$ levels at 5:00 p.m. $(\mathrm{p}<0.01)$ and $+95 \%$ increase at 8:00 p.m. among healthy men $(\mathrm{p}<0.05)$ (Table 3$)$ [77]. A similar period (i.e., $40 \mathrm{~h}$ ) of sleep deprivation investigated by Frey et al. [99] has also been found to induce a significant increase from baseline in the morning and afternoon levels of IL-1 $(p<0.05)$ (Table 2). Similar to Bøyum et al. [93], Frey et al. [99] have also found that severe sleep deprivation resulted in a decrease in IL-6 levels throughout most of the day $(\mathrm{p}<0.05)$ (Table 3$)$.

Conversely, Vgontzas et al. [100] have reported that the 24-h secretion of IL-6 increased when sleep was restricted to 6-h per night for one week $(\mathrm{p}<0.05)$ (Table 3). Additionally, Vgontzas et al. [100] have found that a multi-day sleep restriction period was associated with an increased 24-h secretion of TNF- $\alpha$ in men only $(\mathrm{p}<0.01)$ (Table 3). As previously mentioned, the inconsistent findings for IL-6 levels, could in part be due to the pro- and anti-inflammatory roles of this cytokine [98]. Furthermore, the variable findings for IL-6 indicate that this marker responds differently to a short period of total sleep deprivation (i.e., 40-h) compared to a week of modest sleep restriction $[99,100]$. 


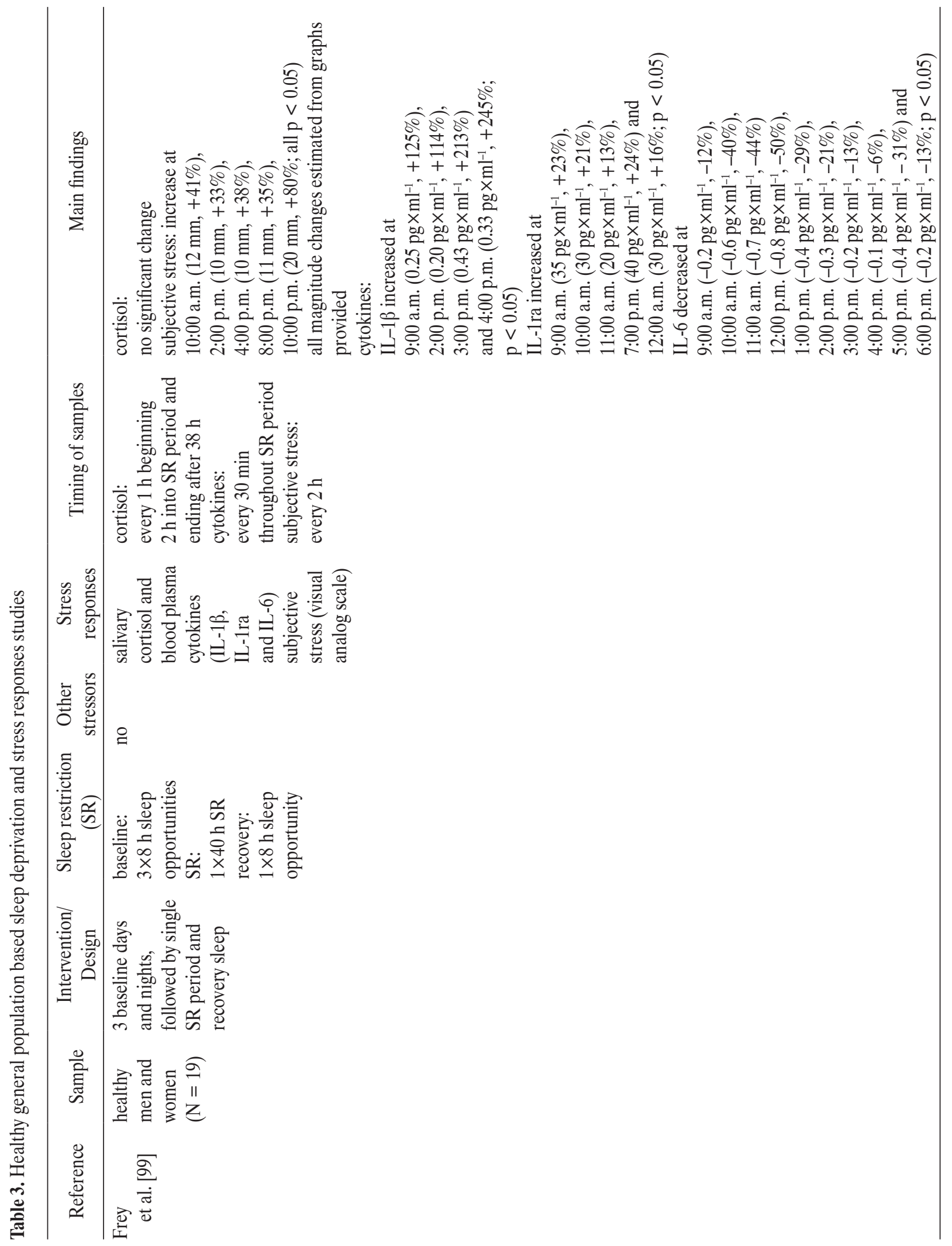



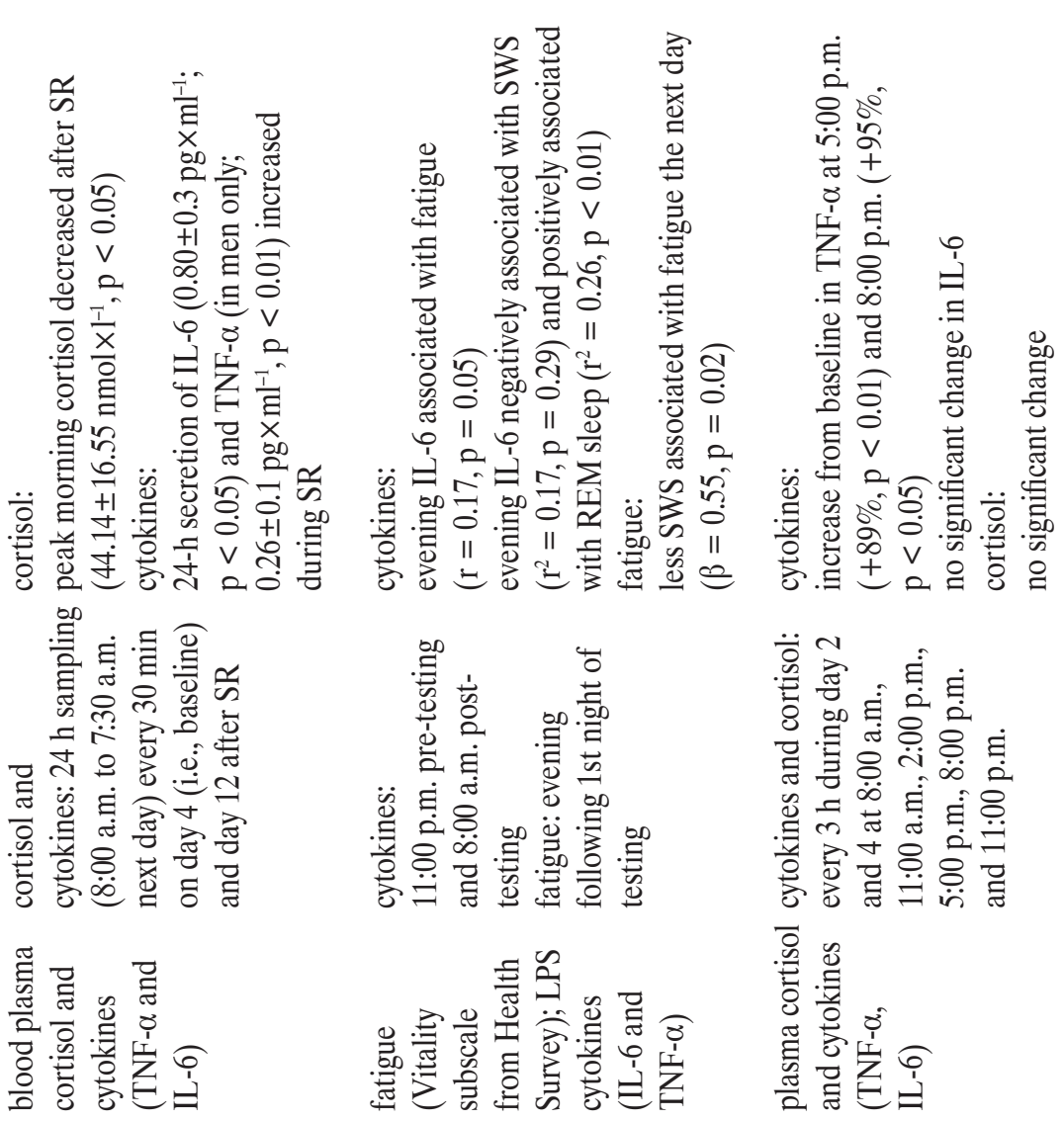

ㅇ

@
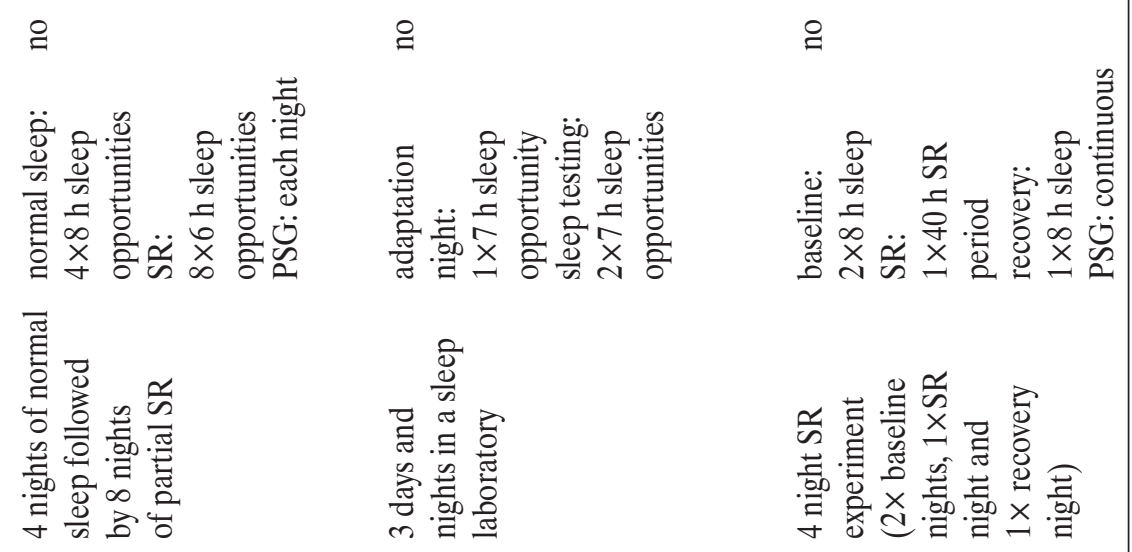

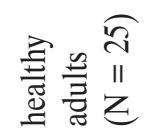

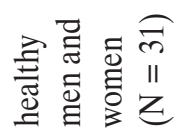

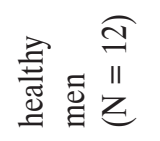

$$
\text { 急 }
$$

兽

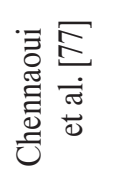




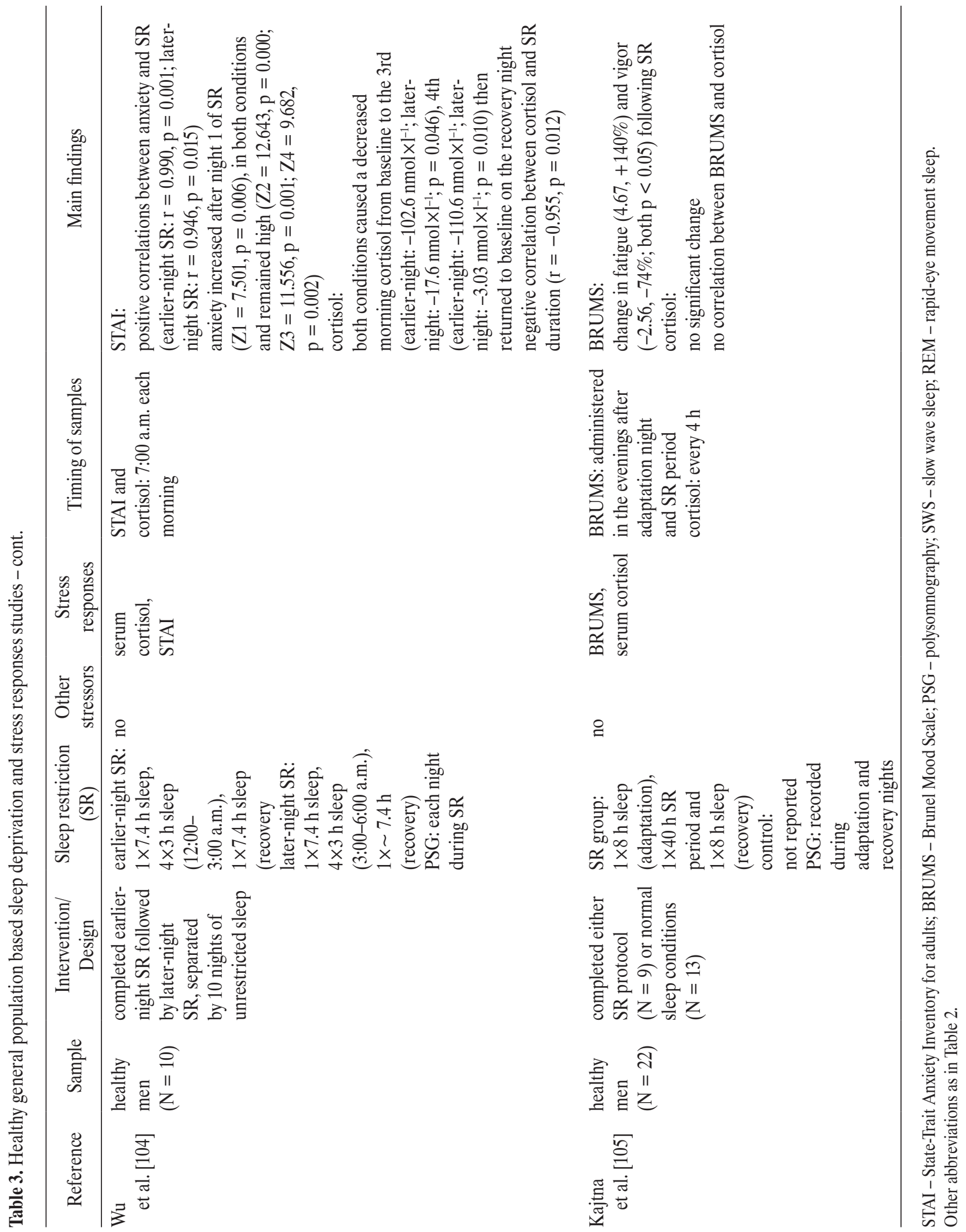


Sleep restriction and simultaneous cortisol and cytokine changes In addition to cytokines, Gundersen et al. [94] have found soldiers' cortisol levels increased from baseline on day $2(+79 \%)$ and day $4(+74 \%)$ of training, while Lundeland et al. [97] have reported increased cortisol levels on day $3(+22 \%)$ and day $5(+73 \%)$. But similarly to IL-6, cortisol had returned towards baseline levels by day 7 (Table 2) $[94,97]$. The simultaneous increase of both cytokine and cortisol levels is similar to what has been observed among individuals with stress-related illness (e.g., depression, metabolic syndrome, CVD) $[28,30,31,101]$ and therefore, could indicate dysregulation of the bi-directional feedback loop [28,30,31]. However, given that some of these markers returned towards baseline levels by completion of the military training, it is likely that the soldiers' endocrine and inflammatory processes were able to adapt to the stressors of sleep restriction and physical work to prevent adverse outcomes [94].

Similar to other military-based studies in this area [80,81,93], Gundersen et al. [94] have not controlled for sleep duration or frequency and the participants also performed continuous physical work and had a reduced energy intake. Both physical work and energy restriction are stressors capable of causing a change in cytokine [102] and/or cortisol levels [84,85]. Therefore, while these [94,97] and other multi-day military-based studies $[80,81,93]$ provide an insight into the effect sleep restriction may have on personnel's acute cytokine and/ or cortisol response, the lack of scientific control demonstrated in available military-based literature [80,81,93,94] clouds the true relationship between the stress of sleep restriction and immune and hormonal responses among emergency service personnel.

Furthermore, the demands investigated in these studies are military-specific. For instance, the extreme sleep restriction endured by military personnel differs somewhat to the moderate, partial sleep restriction civilian emergency service personnel, such as police, firefighters and paramedics, are typically exposed to [55,60,61]. Yet, given the possible dysregultion of the cytokine and cortisol bi-directional feedback loop, further research should be focused on determining how varying amounts of controlled sleep restriction may affect emergency personnel's hormonal and immunological responses.

While Gundersen et al. [94] and Lundeland et al. [97] have reported that cortisol and cytokine levels were able to recover towards baseline, there is currently insufficient emergency service literature from which one could draw conclusions regarding the optimal recovery time for personnel exposed to sleep restriction. Therefore, further investigation is needed to determine, more specifically, the amount and/or number of recovery sleep(s) required for hormonal and inflammatory markers to recover following various types of emergency work (e.g., firefighting and police work).

Such investigations may assist emergency services in optimizing work/shift structures to minimize negative stress-related health outcomes while still meeting the unique staffing demands (e.g., on-call, response capabilities, and mobilizing for multi-day emergencies) of their organizations.

\section{The impact of sleep restriction on mood state among emergency service personnel}

In addition to physiological responses, restricted and/or poor quality sleep may also adversely affect emergency workers psychological functioning [31,82,83]. Slaven et al. [106] have investigated self-reported depressive symptoms and sleep quality among police officers who completed the Centre for Epidemiological Studies Depression (CES-D) and Pittsburgh Sleep Quality Index (PSQI) questionnaires. The findings revealed strong correlations between both measures.

For instance, mean CES-D depressive symptom scores increased across increasing quintiles of the PSQI global sleep quality score for males and females $(p<0.001)$, 
indicating that depressive symptoms in male and female officers significantly increased as subjective sleep quality deteriorated [106]. However, the use of self-report measures when investigating sleep may be negatively affected by reporting/recall bias, demonstrated by a propensity to subjectively overestimate sleep length [107]. While it should be noted that the CES-D is highly sensitive to sleep, which is reflected in this study by the strong correlation between depression and sleep among officers, future research would benefit from more objective sleep measures (e.g., activity monitors, polysomnography). Furthermore, the cross-sectional design of this study [106] limits the ability to make causal inferences.

Prospective study designs, multi-day military-based studies have examined soldiers' psychological responses to periods of objectively measured (i.e., activity monitors) sleep restriction and near constant physical work $[82,83]$. Lieberman et al. [83] have assessed the mood state of soldiers before and after a $53 \mathrm{~h}$ continuous physical combat training exercise in which they had $3 \pm 0.3 \mathrm{~h}$ of total sleep. Using the Profile of Moods States (POMS), Lieberman et al. [83] have reported a significant change from pre- to post-training in each of the mood subscales (i.e., tension, depression, confusion, fatigue, anger and vigor) (Table 2). In a more recent study, Lieberman et al. [82] have assessed soldiers' mood also using POMS during an 84-h laboratory-based military training simulation, which controlled for the length and frequency of sleep opportunities (i.e., $7 \times 1$-h sleep breaks) and the type and duration of military activities per day. Over the course, the soldiers had a total of $6.2 \pm 0.4 \mathrm{~h}$ of sleep, and like their earlier study, all mood subscales significantly worsened over the duration of the training (Table 2). These findings indicate that decrements in mood can persist with $6 \mathrm{~h}$ of total sleep while performing an extended (i.e., 84-h) period of physical military work under more controlled laboratory settings.

Both the above mentioned studies [82,83] failed to include a control group. Consequently, it is difficult to determine how much of the reported change in psychological responses were due to the lack of sleep, or a combination of other stressors present (e.g., physical work and energy restriction). Therefore, it is not possible to know which of the stressors, or which combination of stressors is the most damaging. Accordingly, caution should be taken when generalizing findings from multi-day military-based studies to other emergency services (e.g., firefighting, police, emergency medical) routinely exposed to different occupational demands (e.g., only partial sleep deprivation or more intermittent physical work) [52].

Furthermore, these studies $[82,83]$ used wrist-worn activity monitors to determine the participants' sleep duration and frequency. Although suited to field research, caution should be taken when using activity monitors to measure more complex sleep parameters (e.g., sleep architecture) [108]. As a result, it is difficult to determine for certain whether the psychological stress responses observed in these studies are attributed to reduced sleep duration alone or changes to sleep architecture.

\section{Impact of sleep restriction on psycho-physiological stress responses among emergency service personnel}

To date only a limited number of studies have investigated psycho-physiological responses to sleep restriction $[103,105,109,110]$ and none has been an emergency service-based study. Thomas et al. [103] have reported that evening stimulated production of IL- 6 in healthy adults was weakly associated with subjective feelings of fatigue the next day $(r=0.17 ; \mathrm{p}=0.05)$ and have concluded that this relationship was mediated by a reduced amount of slow wave sleep (SWS). Indeed, earlier studies have also reported that increases in circulating levels of IL-6 correlate with decreases in SWS [111,112].

A number of studies have also examined interaction between cortisol and psychological responses to various stressors $[25,48]$, yet only a small number of studies have investigated how sleep restriction, specifically, may affect 
the interaction between these responses $[105,109,110]$. Furthermore, such studies have generally focused on participants with either a sleep disorder or mental illness $[109,110]$ and therefore, were not included in this review. Indeed, to the best of the authors' knowledge, only one study has examined interaction between subjective mood (assessed using the Brunel mood scale) and cortisol levels pre and post a 40-h period of sleep deprivation [105]. However, no correlation has been reported between responses in this study [105]. As such, future research needs to determine whether psycho-physiological relationships exist among healthy emergency responders (free of clinical mental and/or sleep disorders) exposed to acute sleep restriction on the job.

While emergency service research is yet to examine statistical relationships (e.g., correlation) between psychophysiological changes to sleep restriction, Lieberman et al. [83] have simultaneously investigated soldiers' psychological and physiological responses to sleep loss during simulated combat. As previously described, the soldiers received minimal sleep and had a restricted energy intake while completing a field-exercise that involved almost continuous physical work in an intermittently hot environment (Table 2) [83]. The soldiers completed the POMS questionnaire pre-, during and post-field and cortisol was measured at 6:00 a.m., 12:00 p.m. and 6:00 p.m.

The results demonstrated that the soldiers' mood, including vigor, fatigue, confusion, depression and tension, significantly deteriorated from pre- to post-field (Table 2) [83]. Furthermore, the post hoc analysis of cortisol revealed lower levels in the morning and higher levels in the evening during the field-exercise compared to the pre-field levels [83]. In addition, evening cortisol measurements on day 3 and 4 during the combat training were higher than pre-training samples [83]. The low morning and high evening cortisol levels reported by Lieberman et al. [83] could indicate a disrupted cortisol circadian rhythm. Indeed, previous research has demonstrated that a low awakening cortisol response and high evening cortisol levels have both been associated with negative health outcomes (e.g., depression) [113].

On the other hand, the increase in the evening cortisol levels reported by Lieberman et al. [83] could also indicate that the participants were more active than usual at these times due to the around-the-clock physical work involved in the military training. Consequently, an inadequate (i.e., low) cortisol response in this instance could be problematic and indicate another component of allostatic load [90]. Given how the cortisol response to different stressors can vary (e.g., prolonged and inadequate responses), yet still indicate possible dysregulation of the HPA-axis highlights the need to investigate all aspects of this physiological stress response in future studies.

Moreover, investigating how the cortisol response interacts with other psychological stress responses could help to further contextualize the significance of the response [28]. Indeed the acute psychological and physiological findings by Lieberman et al. [83] may demonstrate that the deterioration in mood during the military training could be associated with a disrupted cortisol response (i.e., low morning and high evening levels). Yet without statistical analysis of the interactions between these markers, it is difficult to determine what the psycho-physiological relationship was (under these conditions).

The lack of a control group is a further limitation of this study [83], making it challenging to determine if the findings were due to sleep restriction, other stressors (i.e., heat stress, energy restriction and physical work) or a combination of these demands. However, this study [83] represents the only available emergency service-based research that examines concurrent changes in the acute psychological and physiological responses to sleep restriction.

Laboratory-based sleep studies [99,104] have also demonstrated concurrent physiological and psychological changes similar to those observed in the field by Lieberman et al. [83]. Using a crossover study design, Wu et al. [104] 
have investigated the effect of an earlier-night (i.e., sleep from 12:00 to 3:00 a.m.) and later-night (i.e., sleep from 3:00 to 6:00 a.m.) sleep restriction protocol on subjective anxiety (measured using the State-Trait Anxiety Inventory; STAI) and cortisol levels. For each condition, the participants completed an unrestricted baseline sleep, 4 nights of sleep restriction followed by a recovery night and blood samples (for cortisol analysis) were taken each morning (at 7:00 a.m.) [104].

In both conditions, STAI increased from baseline after the 1st night of reduced sleep and then continued to increase each day for the duration of the conditions [104]. Furthermore, positive correlations between STAI and sleep restriction (earlier-night sleep restriction: $r=0.990, p=0.00$; later-night sleep restriction: $r=0.946$, $p=0.015$ ) were reported and both sleep periods resulted in the reduced morning cortisol levels [104]. Following the recovery night, cortisol and STAI in both conditions returned towards normal, but only cortisol reached baseline. While this study explored more controlled sleep periods, additional daily samples were needed to provide a more detailed measure of circadian changes in hormonal and mood responses.

Furthermore, the lack of statistical analyses between the psychological and physiological responses limits the ability to investigate any possible psycho-physiological interactions in response to the periods of sleep restriction examined.

In more extreme cases (e.g., natural or man-made disasters such as large bushfires/wildfires), emergency personnel have reported continuous periods of extended wakefulness lasting for more than 24-h [55]. When examined in controlled laboratory conditions, total sleep deprivation was found by Frey et al. [99] to elicit simultaneous physiological and psychological changes among healthy adults. For instance, Frey et al. [99] have reported a simultaneous increase in inflammatory cytokines (IL-1ra, IL-1b) in the morning and evening and higher subjective stress levels at most time points across the 40-h sleep deprivation period compared with baseline $(p<0.05)$. However, no significant effects for salivary cortisol levels were detected in this study.

\section{CONCLUSIONS}

A single night of sleep deprivation (either partial or full) may not be a sufficient stressor to significantly affect the overall daily release of cortisol among military emergency responders [76]. However, extreme sleep restriction over multiple days of emergency work (e.g., 1-7 h of sleep over 2-7 days) can:

- disrupt the circadian cortisol rhythm [80,81,83],

- disrupt (i.e., above and below baseline or control levels) pro- (i.e., IL-6, TNF- $\alpha$ and IL-1 $\beta$ ) and anti-inflammatory cytokine levels (i.e., IL-1ra) [93,94,97],

- elicit adverse psychological responses (i.e., deterioration in mood) [82,83],

- cause a simultaneous increase in both cortisol and cytokine levels (i.e., IL-6) [94,97].

Taken together, this literature informs emergency services that exposure to more than one night of severe workrelated sleep restriction experienced between shifts may influence their personnel's acute physiological (i.e., cortisol and cytokine levels) and psychological (i.e., mood) functioning.

The significance (i.e., abnormal or normal) of acute changes in physiological and psychological responses to restricted sleep experienced at work is of further importance to emergency services. Extreme sleep restriction over consecutive days of military training can result in the concurrent deterioration of both mood and disrupted diurnal cortisol levels [83,104]. However, interactions between these responses have not yet been statistically analyzed and therefore, it is difficult to determine, for certain, if a psycho-physiological relationship exists between these markers (under these conditions) among personnel. 
Healthy individuals have also demonstrated adverse simultaneous, but not statistically evaluated, changes in multiple physiological (i.e., cortisol and cytokines) and psychological (i.e., STAI) responses following consecutive nights (lasting up to a week) of sleep restriction [100,104]. Conversely, the evidence of psycho-physiological interactions between stress responses following a single night of sleep deprivation remains equivocal $[77,99,105]$. However, it appears that the release of pro-inflammatory cytokines (i.e., IL-6) positively correlates with feelings of fatigue [103], indicating the negative effect immune dysregulation may have on general well-being.

Moreover, this finding offers some limited empirical support for the use of non-invasive measures of fatigue to evaluate immune function. However, on the whole, evidence investigating psycho-physiological responses to sleep restriction is still very limited and inconclusive. Therefore, it is not currently feasible for uniform services to develop practical means to efficiently monitor the acute stress of their personnel in the field, based on psychophysiological interactions.

To date, only a limited number of studies have investigated the effect of work-related sleep restriction on acute stress responses among different forms of emergency personnel. In fact, this review of the literature uncovered only one police-based study [31] and no firefighting or emergency medical-related investigations. Meanwhile, the overwhelming majority of the research was focused on multiday military studies $[80-83,93,94,97]$. As such, the periods of extreme sleep restriction (i.e., 1-2-h per 24-h) investigated are, in most cases, military specific. Furthermore, military-based studies expose personnel to stressors (such as continuous physical military activities and food and fluid restriction) not commonly experienced during more civilian emergency service work (e.g., firefighting and police work) [55,114].

Consequently, extrapolating findings from the defense occupations with different workloads to more civilian emergency services may under or overestimate the potential stress-related implications and lead to inappropriate advice/recommendations regarding sleep opportunities. Additionally, most military field-based studies have not controlled for sleep duration or frequency and failed to include a control group matched for age, sex or work experience.

As a result, it is difficult to determine how much of the reported change in physiological or psychological responses were due to sleep restriction, other occupational stressors or a combination of stressors and therefore, if sleep restriction (or a combination of stressors) was the most damaging stressor. Regardless, it appears that sleep restriction may be a major occupational stressor contributing to the reported physiological and psychological responses and therefore, warrants further investigation.

\section{FUTURE RESEARCH DIRECTIONS}

To further understand the impact of work-related sleep restriction on acute stress responses and to provide emergency services with the knowledge they need to protect the health of their personnel, future research should focus on:

- a wider range of emergency services,

- practical methods to monitor physiological and psychological health of the personnel exposed to work related sleep restriction,

- controlled periods of sleep restriction similar in duration to what is reported/experienced among civilian emergency services,

- concurrent measurement of multiple stress responses and statistical analyses of the psycho-physiological interactions (if any) between these responses,

- all aspects of the cortisol and cytokine response (e.g., normal, inadequate and prolonged responses) that characterize the nature and possible dysregulation of these systems,

- the amount and/or number of recovery sleep(s) required for cortisol and cytokine levels to return to baseline following work-related sleep restriction. 
While the acute effect that work-related sleep restriction has on stress remains an important focus, future research could also benefit from longitudinal/follow-up studies to further understand the possible link between this stressor and negative long-term health outcomes. For instance, examining how stress responses recover following exposure to sleep restriction (via post/follow-up testing) during emergency work may provide insights into how acute responses translate into chronic physiological and psychological changes and ultimately, result in adverse long-term health-outcomes.

\section{REFERENCES}

1. Banks S, Dinges DF. Behavioral and physiological consequences of sleep restriction. J Clin Sleep Med. 2007;3(5):19-28.

2. Mullington JM, Simpson NS, Meier-Ewert HK, Haack M. Sleep loss and inflammation. Best Pract Res Clin Endocrinol Metab. 2010;24:775-84, http://dx.doi.org/10.1016/j.beem. 2010.08.014.

3. Vgontzas AN, Papanicolaou DA, Bixler EO, Lotsikas A, Zachman K, Kales A, et al. Circadian interleukin-6 secretion and quantity and depth of sleep. J Clin Endocrinol Metab. 1999;84(8):2603-7, http://dx.doi.org/10.1210/ jcem.84.8.5894.

4. Spiegel K, Leproult R, Van Cauter E. Impact of sleep debt on metabolic and endocrine function. Lancet. 1999;354(9188):1435-9, http://dx.doi.org/10.1016/S01406736(99)01376-8.

5. Peter JH, Mark TOC, Nancy JR, Stephen JH, Jürgens N, Keri LHC, et al. Inflammation in human brain injury intracerebral concentrations of IL-1 $\alpha$, IL-1 $1 \beta$, and their endogenous inhibitor IL-1ra. J Neurotrauma. 2007;24(10):1545-57, http:// dx.doi.org/10.1089/neu.2007.0295.

6. Chung S, Son GH, Kim K. Circadian rhythm of adrenal glucocorticoid: Its regulation and clinical implications. Biochim Biophys Acta. 2011;1812(5):581-91.

7. Zimberg IZ, Dâmaso A, Del Re M, Carneiro AM, de Sá Souza H, de Lira FS, et al. Short sleep duration and obesity:
Mechanisms and future perspectives. Cell Biochem Funct. 2012;30(6):524-9, http://dx.doi.org/10.1002/cbf.2832.

8. Reynolds AC, Dorrian J, Liu PY, Van Dongen HPA, Wittert GA, Harmer LJ, et al. Impact of five nights of sleep restriction on glucose metabolism, leptin and testosterone in young adult men. PLoS One. 2012;7(7):1-10, http://dx.doi. org/10.1371/journal.pone.0041218.

9. Babson KA, Trainor CD, Feldner MT, Blumenthal H. A test of the effects of acute sleep deprivation on general and specific self-reported anxiety and depressive symptoms: An experimental extension. J Behav Ther Exp Psychiatry. 2010;41(3):297-303, http://dx.doi.org/10.1016/ j.jbtep.2010.02.008.

10. Gangwisch JE, Heymsfield SB, Boden-Albala B, Buijs RM, Kreier F, Pickering TG, et al. Short sleep duration as a risk factor for hypertension: Analyses of the first National Health and Nutrition Examination Survey. Hypertension. 2006;47(5):833-9, http://dx.doi.org/10.1161/01. HYP.0000217362.34748.e0.

11. Ganz FD. Sleep and immune function. Crit Care Nurse. 2012;32(2):e19-25, http://dx.doi.org/10.4037/ccn 2012689.

12. Hall MH, Muldoon MF, Jennings JR, Buysse DJ, Flory JD, Manuck SB. Self-reported sleep duration is associated with the metabolic syndrome in midlife adults. Sleep. 2008;31(5):635-43.

13. Finnerty CC, Jeschke MG, Herndon DN, Gamelli R, Gibran N, Klein M, et al. Temporal cytokine profiles in severely burned patients: A comparison of adults and children. Mol Med. 2008;14(9-10):553-60.

14. Myles WS. Self-paced work in sleep deprived subjects. Ergonomics. 1987;30(8):1175-84.

15. Reynolds RM, Labad J, Strachan MWJ, Braun A, Fowkes FGR, Lee AJ, et al. Elevated fasting plasma cortisol is associated with ischemic heart disease and its risk factors in people with type 2 diabetes: The edinburgh type 2 diabetes study. J Clinic Endocrinol Metab. 2010;95(4), http:// dx.doi.org/10.1210/jc.2009-2112. 
16. McCanlies EC, Slaven JE, Smith LM, Andrew ME, Charles LE, Burchfiel CM, et al. Metabolic syndrome and sleep duration in police officers. Work. 2012;43(2):133-9.

17. World Health Organization. Global status report on noncommunicable disaeses 2010. Geneva: WHO; 2011.

18. World Health Organization. Depression. Fact Sheet Number 369. October 2012 [cited 2013 Jun 19]. Available from: http://www.who.int/mediacentre/factsheets/s3369/en/.

19. Aardal-Eriksson E, Eriksson TE, Holm AC, Lundin T. Salivary cortisol and serum prolactin in relation to stress rating scales in a group of rescue workers. Biol Psychiatry. 1999;46(6): 850-5, http://dx.doi.org/10.1016/S0006-3223(98)00381-3.

20. Ryff CD, Singer B. The contours of positive human health. Psychol Inquiry. 1998;9(1):1, http://dx.doi.org/10.1207/ s15327965pli0901_1.

21. Ryff CD, Singer BH. Biopsychosocial challenges of the new millennium. Psychother Psychosom. 2000;69(4):170-7.

22. Brydon L, Walker C, Wawrzyniak A, Whitehead D, Okamura $\mathrm{H}$, Yajima J, et al. Synergistic effects of psychological and immune stressors on inflammatory cytokine and sickness responses in humans. Brain Behav Immun. 2009;23(Suppl 1): 217-24, http://dx.doi.org/10.1016/j.bbi.2008.09.007.

23. Maas CJM, Snijders TAB. The multilevel approach to repeated measures for complete and incomplete data. Qual Quant. 2003;37(1):71, http://dx.doi.org/10.1023/A:102254 5930672.

24. Chiodo S, Tessitore A, Cortis C, Cibelli G, Lupo C, Ammendolia A, et al. Stress-related hormonal and psychological changes to official youth Taekwondo competitions. Scand J Med Sci Sports. 2011;21(1):111-9, http://dx.doi. org/10.1111/j.1600-0838.2009.01046.x.

25. Jürimäe J, Mäestu J, Purge P, Jürimäe T, Sööt T. Relations among heavy training stress, mood state and performance for male junior rowers. Percept Mot Skills. 2002;95(2): 520-6, http://dx.doi.org/10.2466/pms.2002.95.2.520.

26. Besedovsky HO, Rey A. The cytokine-HPA axis feed-back circuit. Zeitschrift Rheumatologie. 2000;59 (Suppl 2):II2630, http://dx.doi.org/10.1007/s003930070014.
27. Eskandari F, Sternberg EM. Neural-immune interactions in health and disease. Ann Ny Acad Sci. 2002;966:20-7, http:// dx.doi.org/10.1111/j.1749-6632.2002.tb04198.x.

28. Silverman MN, Sternberg EM. Glucocorticoid regulation of inflammation and its functional correlates: From HPA axis to glucocorticoid receptor dysfunction. Ann Ny Acad Sci. 2012;1261(1):55-63, http://dx.doi.org/10.1111/j.17496632.2012.06633.x.

29. Sternberg EM, Licinio J. Overview of neuroimmune stress interactions. Implications for susceptibility to inflammatory disease. Ann Ny Acad Sci. 1995;771:364-71, http://dx.doi. org/10.1111/j.1749-6632.1995.tb44695.x.

30. Makhija K, Karunakaran S. The role of inflammatory cytokines on the aetiopathogenesis of depression. Aust N Z J Psychiatry. 2013, http://dx.doi.org/10.1177/0004867413488220.

31. Zunszain PA, Anacker C, Cattaneo A, Carvalho LA, Pariante CM. Glucocorticoids, cytokines and brain abnormalities in depression. Prog Neuropsychopharmacol. 2011; 35(3):722-9, http://dx.doi.org/10.1016/j.pnpbp.2010.04.011.

32. Kunz-Ebrecht SR, Kirschbaum C, Marmot M, Steptoe A. Differences in cortisol awakening response on work days and weekends in women and men from the Whitehall II cohort. Psychoneuroendocrinology. 2004;29(4):516-28, http:// dx.doi.org/10.1016/S0306-4530(03)00072-6.

33. Mackin P, Young AH. The role of cortisol and depression: Exploring new opportunities for treatments. Psychiatr Times. 2004;21(5):92-5.

34. Pella D, Otsuka K, Singh RB. Metabolic syndrome: A disease of the brain. Open Nutraceutic J. 2011;4(1):107-18, http://dx.doi.org/10.2174/1876396001104010107.

35. Pickup JC, Crook MA. Is type II diabetes mellitus a disease of the innate immune system? Diabetologia. 1998;41(10): 1241-8, http://dx.doi.org/10.1007/s001250051058.

36. Ridker PM, Rifai N, Stampfer MJ, Hennekens CH. Plasma concentration of interleukin- 6 and the risk of future myocardial infarction among apparently healthy men. Circulation. 2000;101(15):1767-72, http://dx.doi.org/10. 1161/01.CIR.101.15.1767. 
37. Cesari M, Penninx BWJ, Newman AB, Kritchevsky SB, Nicklas BJ, Sutton-Tyrrell K, et al. Inflammatory markers and onset of cardiovascular events: results from the Health ABC study. Circulation. 2003;108(19):2317-22, http://dx. doi.org/10.1161/01.CIR.0000097109.90783.FC.

38. Bennet AM, van Maarle MC, Hallqvist J, Morgenstern R, Frostegård J, Wiman B, et al. Association of TNF-alpha serum levels and TNFA promoter polymorphisms with risk of myocardial infarction. Atherosclerosis. 2006;187(2):408-14, http://dx.doi.org/10.1016/j.atherosclerosis.2005.09.022.

39. You TJ, Nicklas BJ, Ding JZ, Penninx BWJH, Goodpaster BH, Bauer DC, et al. The metabolic syndrome is associated with circulating adipokines in older adults across a wide range of adiposity. J Gerontol A Biol. 2008;63(4):414-9, http://dx.doi.org/10.1093/gerona/63.4.414.

40. Hiles SA, Baker AL, de Malmanche T, Attia J. A meta-analysis of differences in IL-6 and IL-10 between people with and without depression: Exploring the causes of heterogeneity. Brain Behav Immun. 2012;26(7):1180-8, http://dx.doi. org/10.1016/j.bbi.2012.06.001.

41. Liu Y, Ho RC-M, Mak A. Interleukin (IL)-6, tumour necrosis factor alpha (TNF- $\alpha$ ) and soluble interleukin-2 receptors (sIL-2R) are elevated in patients with major depressive disorder: A meta-analysis and meta-regression. J Affect Disord. 2012;139(3):230-9, http://dx.doi.org/10.1016/j.jad.2011.08.003.

42. Doane LD, Franz CE, Prom-Wormley E, Eaves LJ, Mendoza SP, Hellhammer DH, et al. Negative emotionality, depressive symptoms and cortisol diurnal rhythms: Analysis of a community sample of middle-aged males. Horm Behav. 2011;60(2):202-9, http://dx.doi.org/10.1016/j.yhbeh. 2011.05.003.

43. Heaney JLJ, Phillips AC, Carroll D. Ageing, depression, anxiety, social support and the diurnal rhythm and awakening response of salivary cortisol. Int J Psychophysiol. 2010; 78(3):201-8, http://dx.doi.org/10.1016/j.ijpsycho.2010.07.009.

44. Reynolds RM, Walker BR. Human insulin resistance: The role of glucocorticoids. Diabetes Obes Metab. 2003;5(1): 5-12, http://dx.doi.org/10.1046/j.1463-1326.2003.00221.x.
45. Walker BR, Soderberg S, Lindahl B, Olsson T. Independent effects of obesity and cortisol in predicting cardiovascular risk factors in men and women. J Intern Med. 2000;247(2):198-204, http://dx.doi.org/10.1046/j.1365-2796. 2000.00609.x.

46. Filipovský J, Ducimetiére P, Eschwége E, Richard JL, Rosselin G, Claude JR. The relationship of blood pressure with glucose, insulin, heart rate, free fatty acids and plasma cortisol levels according to degree of obesity in middleaged men. J Hypertens. 1996;14(2):229-35, http://dx.doi. org/10.1097/00004872-199602000-00012.

47. Fortmann SP, Ford E, Criqui MH, Folsom AR, Harris TB, Hong Y, et al. CDC/AHA workshop on markers of inflammation and cardiovascular disease: Application to clinical and public health practice: Report from the population science discussion group. Circulation. 2004;110(25):e554-9, http://dx.doi.org/10.1161/01.CIR.0000148982.95775.BF.

48. Bouget M, Rouveix M, Michaux O, Pequignot J, Filaire E. Realationships among training stress mood and dehydroepiandrosterone sulphate/cortisol ratio in female cyclists. J Sport Sci. 2006;24(12):1297-302, http://dx.doi. org/10.1080/02640410500497790.

49. Filaire E, Legrand B, Lac G, Pequignot J. Training of elite cyclists: Effects on mood state and selected hormonal responses. J Sport Sci. 2004;22:1025-33, http://dx.doi.org/10. 1080/02640410410001716751.

50. Burl S, Townend J, Njie-Jobe J, Cox M, Adetifa UJ, Touray E, et al. Age-dependent maturation of Toll-like receptor-mediated cytokine responses in Gambian infants. Plos One. 2011;6(4):e18185, http://dx.doi.org/10.1371/journal.pone.0018185.

51. Vgontzas AN, Zoumakis M, Bixler EO, Lin H-M, Prolo P, Vela-Bueno A, et al. Impaired nighttime sleep in healthy old versus young adults is associated with elevated plasma interleukin-6 and cortisol levels: Physiologic and therapeutic implications. J Clinical Endocrinol Metab. 2003;88(5):2087-95, http://dx.doi.org/10.1210/ jc.2002-021176. 
52. Aisbett B, Wolkow A, Sprajcer M, Ferguson S. "Awake, smoky, and hot": Providing an evidence-base for managing the risks associated with occupational stressors encountered by wildland firefighters. Appl Ergon. 2012;43(5):916-25, http://dx.doi.org/10.1016/j.apergo.2011.12.013.

53. Aisbett B, Phillips M, Nichols D. Work patterns of tankerbased bushfire suppression by Australian volunteer firefighters in south-east Australia. Paper presented at the Tassie Fire Conference: The Joint Australasian Fire Authorities Council/Bushfire Co-Operative Research Centre Conference; 2007 Sept 21; Hobart, Tasmania, Australia [cited 2013 Oct 16]. Available from: http://www.proceedings.com.au/ tassiefire/powerpoint_pdf/Fri\%201400\%20Ballroom $\% 20$ 2\%20Aisbett.pdf.

54. Black JL. Heat stress in bushfire fighters: A practitioner's perspective. In: Hales JRS, editor. Heat stress: physical exertion and environment. East Melbourne: The Menzies Foundation; 1987. p. 29-36.

55. Cater H, Clancy D, Duffy K, Holgate A, Wilson B, Wood J. Fatigue on the fireground: The DPI experience. Paper presented at the Tassie Fire Conference: The Joint Australasian Fire Authorities Council/Bushfire Co-Operative Research Centre Conference; 2007 Sep 21; Hobart, Tasmania, Australia [cited 2013 Dec 10]. Available from: http://proceedings. com.au/tassiefire/papers_pdf/fri_wilson.pdf.

56. Cuddy JS, Gaskill SE, Sharkey BJ, Harger SG, Ruby BC. Supplemental feedings increase self-selected work output during wildfire suppression. Med Sci Sports Exerc. 2007;39(6): 1004-12, http://dx.doi.org/10.1249/mss.0b013e318040b2fb.

57. Elliott G, Omodei M, Johnson C. How human factors drive decision making at fire ground level. Bushfire Co-Operative Research Centre FireNote 2009 [cited 2013 Oct 10]. Available from: http://www.bushfirecrc.com/managed/resource/0909_hf_firenote44_lowres.pdf.

58. Reisen F, Hansen D, Meyer CP. Exposure to bushfire smoke during prescribed burns and wildfires: Firefighters' exposure risks and options. Environ Int. 2011;37(2):314-21, http:// dx.doi.org/10.1016/j.envint.2010.09.005.
59. Hunter L. The Campaign Fires: North-East/East Gippsland Fires 2003. Mt. Waverley, Vic.: Country Fire Authority; 2003. 60. Guyon A, Balbo M, Morselli LL, Tasali E, Leproult R, L'Hermite-Balériaux M, et al. Adverse effects of 2 nights of sleep restriction on the hypothalamic-pituitary-adrenal axis in healthy men. J Clin Endocrinol Metab. 2014;99(8): 2861-8, http://dx.doi.org/10.1210/jc.2013-4254.

61. Neylan TC, Metzler TJ, Best SR, Weiss DS, Fagan JA, Liberman A, et al. Critical incident exposure and sleep quality in police officers. Psychosom Med. 2002;64(2):345-52, http:// dx.doi.org/10.1097/00006842-200203000-00019.

62. Cook B, Mitchell W. Occupational health effects for firefighters: The extent and implications of physical and psychological injuries. Centre of Full Employment and Equity, Equity CoFEa; 2013 [cited 2013 Oct 10]. Available from: https://www.firecrisis.com.au/wp-content/uploads/2013/02/ CofFEE-report-Final.pdf.

63. Van Mark A, Weiler SW, Schröder M, Otto A, Jauch-Chara K, Groneberg DA, et al. The impact of shift work induced chronic circadian disruption on IL- 6 and TNF- $\alpha$ immune responses. J Occup Med Toxicol. 2010;5:18-22, http://dx.doi. org/10.1186/1745-6673-5-18.

64. Hartley TA, Burchfiel CM, Fekedulegn D, Andrew ME, Violanti JM. Health disparities in police officers: Comparisons to the U.S. general population. Int J Emerg Mental Health. 2011;13(4):211-20.

65. Rajaratnam SM, Barger LK, Lockley SW, Shea SA, Wang W, Landrigan CP, et al. Sleep disorders, health, and safety in police officers. JAMA. 2011;306(23):2567-78, http://dx.doi. org/10.1001/jama.2011.1851.

66. Abedelmalek S, Souissi N, Chtourou H, Denguezli M, Aouichaoui C, Ajina M, et al. Effects of partial sleep deprivation on proinflammatory cytokines, growth hormone, and steroid hormone concentrations during repeated brief sprint interval exercise. Chronobiol Int. 2013;30(4):502-9, http://dx.doi.org/10.3109/07420528.2012.742102.

67. Pejovic S, Basta M, Vgontzas AN, Kritikou I, Shaffer ML, Tsaoussoglou M, et al. Effects of recovery sleep after one 
work week of mild sleep restriction on interleukin-6 and cortisol secretion and daytime sleepiness and performance. Am J Physiol Endocrinol Metab. 2013;305(7):E890-6, http://dx.doi.org/10.1152/ajpendo.00301.2013.

68. Courtney J, Francis A, Paxton S. Caring for the country: Fatigue, sleep and mental health in Australian rural paramedic shiftworkers. J Community Health. 2013;38(1):17886, http://dx.doi.org/10.1007/s10900-012-9599-z.

69. Gleeson M, Blannin AK, Walsh NP, Bishop NC, Clark AM. Effect of low- and high-carbohydrate diets on the plasma glutamine and circulating leukocyte responses to exercise. Int J Sport Nutr. 1998;8(1):49-59.

70. Faraut B, Boudjeltia KZ, Dyzma M, Rousseau A, David E, Stenuit P, et al. Benefits of napping and an extended duration of recovery sleep on alertness and immune cells after acute sleep restriction. Brain Behav Immun. 2011;25(1):16-24, http://dx.doi.org/10.1016/j.bbi. 2010.08.001.

71. Shiozaki M, Miyai N, Morioka I, Utsumi M, Koike H, Arita $\mathrm{M}$, et al. [Assessment of the risk of ischemic heart disease and its relevant factors among Japanese police officers]. Sangyo Eiseigaku Zasshi. 2013;55(4):115-24. Japanese.

72. Charles LF, Ja KG, Andrew ME, Violanti JM, Fekedulegn D, Burchfiel CM. Sleep duration and biomarkers of metabolic function among police officers. J Occup Environ Med. 2011;53(8):831-7, http://dx.doi.org/10.1097/JOM. 0b013e31821f5ece.

73. Silverman MN, Heim CM, Nater UM, Marques AH, Sternberg EM. Neuroendocrine and immune contributors to fatigue. PM R. 2010;2(5):338-46, http://dx.doi.org/10.1016/ j.pmrj.2010.04.008.

74. Peterson AL, Goodie JL, Satterfield WA, Brim WL. Sleep disturbance during military deployment. Mil Med. 2008;173(3):230-5.

75. Moore J, Harper Smith A, Felice U, Walsh N. Three nights of sleep deprivation does not alter thermal strain during exercise in the heat. Eur J Appl Physiol. 2013;113(9):2353-60, http://dx.doi.org/10.1007/s00421-013-2671-2.
76. Goh VH, Tong TY, Lim C, Low EC, Lee LK. Effects of one night of sleep deprivation on hormone profiles and performance efficiency. Mil Med. 2001;166(5):427-31.

77. Chennaoui M, Sauvet F, Drogou C, Van Beers P, Langrume C, Guillard M, et al. Effect of one night of sleep loss on changes in tumor necrosis factor alpha (TNF- $\alpha$ ) levels in healthy men. Cytokine. 2011;56(2):318-24, http://dx.doi. org/10.1016/j.cyto.2011.06.002.

78. Pejovic S, Vgontzas AN, Basta M, Tsaoussoglou M, Zoumakis E, Vgontzas A, et al. Leptin and hunger levels in young healthy adults after one night of sleep loss. J Sleep Res. 2010;19(4):552-8, http://dx.doi.org/10.1111/j.13652869.2010.00844.x.

79. Weckesser LJ, Plessow F, Pilhatsch M, Muehlhan M, Kirschbaum C, Miller R. Do venepuncture procedures induce cortisol responses? A review, study, and synthesis for stress research. Psychoneuroendocrinology. 2014;46:88-99, http:// dx.doi.org/10.1016/j.psyneuen.2014.04.012.

80. Opstad PK. Circadian rhythm of hormones is extinguished during prolonged physical stress, sleep and energy deficiency in young men. Eur J Endocrinol. 1994;131(1):56-66, http:// dx.doi.org/10.1530/eje.0.1310056.

81. Opstad PK, Aakvaag A. The effect of a high calory diet on hormonal changes in young men during prolonged physical strain and sleep deprivation. Eur J Appl Physiol. 1981;46(1):31-9, http://dx.doi.org/10.1007/BF00422172.

82. Lieberman HR, Niro P, Tharion WJ, Nindl BC, Castellani JW, Montain SJ. Cognition during sustained operations: Comparison of a laboratory simulation to field studies. Aviat Space Environ Med. 2006;77(9):929-35.

83. Lieberman HR, Bathalon GP, Falco CM, Kramer FM, Morgan CA, Niro P. Severe decrements in cognition function and mood induced by sleep loss, heat, dehydration, and undernutrition during simulated combat. Biol Psychiatry. 2005;57:422-9, http://dx.doi.org/10.1016/j.biopsych. 2004.11.014.

84. Tomiyama AJ, Mann T, Vinas D, Hunger JM, Dejager J, Taylor SE. Low calorie dieting increases cortisol. Psychosom 
Med. 2010;72(4):357-64, http://dx.doi.org/10.1097/PSY. 0b013e3181d9523c.

85. Georgopoulos NA, Rottstein L, Tsekouras A, Theodoropoulou A, Koukkou E, Mylonas P, et al. Abolished circadian rhythm of salivary cortisol in elite artistic gymnasts. Steroids. 2011;76(4):353-7, http://dx.doi.org/10.1016/j.stero ids.2010.10.013.

86. Viru AM, Hackney AC, Välja E, Karelson K, Janson T, Viru M. Influence of prolonged continuous exercise on hormone responses to subsequent exercise in humans. Eur J Appl Physiol. 2001;85(6):578-85, http://dx.doi.org/10.1007/ s004210100498.

87. Juster R-P, McEwen BS, Lupien SJ. Allostatic load biomarkers of chronic stress and impact on health and cognition. Neurosci Biobehav Rev. 2010;35(1):2-16, http://dx. doi.org/10.1016/j.neubiorev.2009.10.002.

88. Rosmond R, Dallman MF, Björntorp P. Stress-related cortisol secretion in men: Relationships with abdominal obesity and endocrine, metabolic and hemodynamic abnormalities. J Clin Endocrinol Metab. 1998;83(6):1853-9, http://dx.doi. org/10.1210/jc.83.6.1853.

89. Miller GE, Cohen S, Ritchey AK. Chronic psychological stress and the regulation of pro-inflammatory cytokines: A glucocorticoid-resistance model. Health Psychol. 2002;21(6):53141, http://dx.doi.org/10.1037/0278-6133.21.6.531.

90. McEwen BS, Seeman T. Protective and damaging effects of mediators of stress. Elaborating and testing the concepts of allostasis and allostatic load. Ann NY Acad Sci. 1999;896: 30-47, http://dx.doi.org/10.1111/j.1749-6632.1999.tb08103.x.

91. Golden S, Wand G, Malhotra S, Kamel I, Horton K. Reliability of hypothalamic-pituitary-adrenal axis assessment methods for use in population-based studies. Eur J Epidemiol. 2011;26: 511-25, http://dx.doi.org/10.1007/s10654-011-9585-2.

92. Smyth N, Clow A, Thorn L, Hucklebridge F, Evans P. Delays of 5-15 min between awakening and the start of saliva sampling matter in assessment of the cortisol awakening response. Psychoneuroendocrinology. 2013;38(9):1476-83, http://dx.doi.org/10.1016/j.psyneuen.2012.12.013.
93. Bøyum A, Wiik P, Gustavsson E, Veiby OP, Reseland J, Haugen $\mathrm{AH}$, et al. The effect of strenuous exercise, calorie deficiency and sleep deprivation on white blood cells, plasma immunoglobulins and cytokines. Scand J Immunol. 1996;43(2): 228-35, http://dx.doi.org/10.1046/j.1365-3083.1996.d01-32.x.

94. Gundersen Y, Opstad P, Reistad T, Thrane I, Vaagenes P. Seven days' around the clock exhaustive physical exertion combined with energy depletion and sleep deprivation primes circulating leukocytes. Eur J Appl Physiol. 2006; 97(2):151-7, http://dx.doi.org/10.1007/s00421-006-0150-8.

95. Vgontzas A, Bixler E, Lin H, Prolo P, Trakada G. IL-6 and its circadian secretion in humans. Neuroimmunomodulation. 2005;12:131-40, http://dx.doi.org/10.1159/000084844.

96. Shearer WT, Reuben JM, Mullington JM, Price NJ, Lee BN, Smith EO, et al. Soluble TNF-alpha receptor 1 and IL-6 plasma levels in humans subjected to the sleep deprivation model of spaceflight. J Allergy Clin Immun. 2001;107(1):165-70, http://dx.doi.org/10.1067/mai. 2001.112270 .

97. Lundeland B, Gundersen Y, Opstad P-K, Thrane I, Zhang Y, Olaussen RW, et al. One week of multifactorial high-stress military ranger training affects Gram-negative signalling. Scand J Clin Lab Invest. 2012;72(7):547-54, http://dx.doi.org/10.3109/00365513.2012.705017.

98. Xing Z, Gauldie J, Cox G, Baumann H, Jordana M, Lei XF, et al. IL-6 is an antiinflammatory cytokine required for controlling local or systemic acute inflammatory responses. J Clin Invest. 1998;101(2):311-20, http://dx.doi.org/10. 1172/JCI1368.

99. Frey DJ, Fleshner M, Wright KP. The effects of 40 hours of total sleep deprivation on inflammatory markers in healthy young adults. Brain Behav Immun. 2007;21(8):1050-7, http://dx.doi.org/10.1016/j.bbi.2007.04.003.

100. Vgontzas A, Zoumakis E, Bixler E, Lin H, Follett H, Kales A, et al. Adverse effects of modest sleep restriction on sleepiness, performance and inflammatory cytokines. J Clin Endocrinol Metab. 2004;89(5):2119-26, http:// dx.doi.org/10.1210/jc.2003-031562. 
101. Chrousos GP, Kino T. Glucocorticoid action networks and complex psychiatric and/or somatic disorders. Stress. 2007;10(2):213-9, http://dx.doi.org/10.1080/102538 90701292119.

102. Steensberg A, Febbraio MA, Osada T, Schjerling P, van Hall G, Saltin B, et al. Interleukin-6 production in contracting human skeletal muscle is influenced by pre-exercise muscle glycogen content. J Physiol. 2001;537(Pt 2):633-9, http://dx.doi.org/10.1111/j.1469-7793.2001.00633.x.

103. Thomas KS, Motivala S, Olmstead R, Irwin MR. Sleep depth and fatigue: Role of cellular inflammatory activation. Brain Behav Immun. 2011;25(1):53-8, http://dx.doi. org/10.1016/j.bbi.2010.07.245.

104. Wu H, Zhao Z, Stone WS, Huang L, Zhuang J, He B, et al. Effects of sleep restriction periods on serum cortisol levels in healthy men. Brain Res Bull. 2008;77(5):241-5, http:// dx.doi.org/10.1016/j.brainresbull.2008.07.013.

105. Kajtna T, Štukovnik V, Dolenc Grošelj L. [Effect of acute sleep deprivation on concentration and mood states with a controlled effect of experienced stress]. Zdrav Vestn. 2011;80(5):354-61. Slovenian.

106. Slaven JE, Mnatsakanova A, Burchfield CM, Smith LM, Charles LE, Andrew ME, et al. Association of sleep quality with depression in police officers. Int J Emerg Ment Health. 2011;13(4):267-77.

107. Lauderdale DS, Knutson KL, Yan LL, Liu K, Rathouz PJ. Self-reported and measured sleep duration: How similar are they? Epidemiology. 2008;19(6):838-45, http://dx.doi. org/10.1097/EDE.0b013e318187a7b0.

108. Reid K, Dawson D. Correlation between wrist activity monitor and electrophysiological measures of sleep in a simulated shiftwork environment for younger and older subjects. Sleep. 1999;22(3):378-85.

109. Backhaus J, Junghanns K, Hohagen F. Sleep disturbances are correlated with decreased morning awakening salivary cortisol. Psychoneuroendocrinology. 2004;29(9):1184-91, http://dx.doi.org/10.1016/j.psyneuen.2004.01.010.

110. Bouhuys A, Flentge F, van den Hoofdakker RH. Effects of total sleep deprivation on urinary cortisol, self-rated arousal, and mood in depressed patients. Psychiatry Res. 1990;34:149-62, http://dx.doi.org/10.1016/0165-1781 (90)90016-X.

111. Burgos I, Richter L, Klein T, Fiebich B, Feige B, Lieb K, et al. Increased nocturnal interleukin- 6 excretion in patients with primary insomnia: A pilot study. Brain Behav Immun. 2006;20(3):246-53, http://dx.doi.org/10.1016/ j.bbi.2005.06.007.

112. Hong S, Mills PJ, Loredo JS, Adler KA, Dimsdale JE. The association between interleukin-6, sleep, and demographic characteristics. Brain Behav Immun. 2005;19(2):165-72, http://dx.doi.org/10.1016/j.bbi.2004.07.008.

113. Vreeburg SA, Hoogendijk WJG, DeRijk RH, van Dyck R, Smit JH, Zitman FG, et al. Salivary cortisol levels and the 2-year course of depressive and anxiety disorders. Psychoneuroendocrinology. 2013;38(9):1494-502, http:// dx.doi.org/10.1016/j.psyneuen.2012.12.017.

114. Ruby BC, Shriver T, Zderic T, Sharkey B, Burks C, Tysk S. Total energy expenditure during arduous wildfire suppression. Med Sci Sports Exerc. 2002;34(6):1048-54, http:// dx.doi.org/10.1097/00005768-200206000-00023.

This work is available in Open Access model and licensed under a Creative Commons Attribution-NonCommercial 3.0 Poland License - http://creativecommons.org/ licenses/by-nc/3.0/pl/deed.en. 